\title{
KNOWLEDGE MANAGEMENTS FOR IMPROVEMENT THE COMPETITIVENESS OF ORGANIZATION
}

\author{
Iveta Paulova, Jaromira Vanova, Miroslav Rusko, \\ Edita Hekelova \& Ruzena Kralikova
}
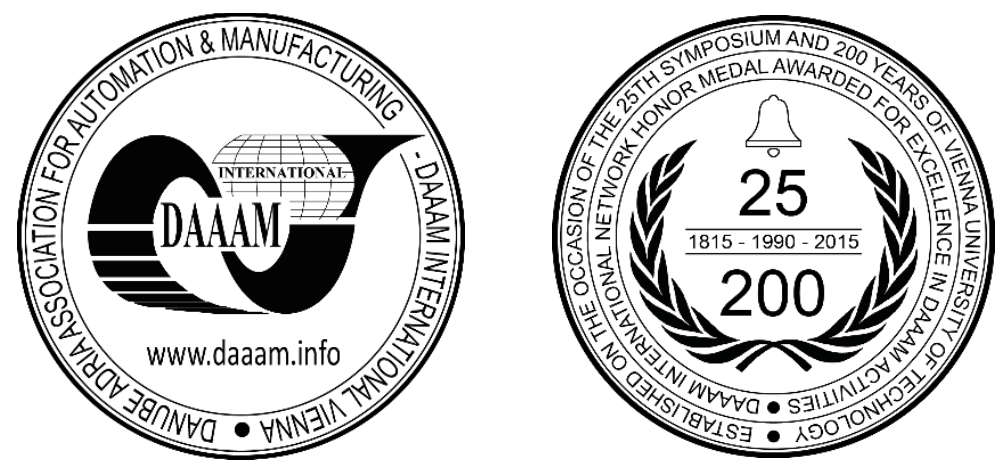

This Publication has to be referred as: Paulova, I[veta]; Vanova, J[aromira]; Rusko, M[iroslav]; Hekelova, E[dita] \& Kralikova, R[uzena] (2017). Knowledge Managements for Improvement the Competitiveness of Organization, Proceedings of the 28th DAAAM International Symposium, pp.1221-1226, B. Katalinic (Ed.), Published by DAAAM International, ISBN 978-3-902734-11-2, ISSN 1726-9679, Vienna, Austria

DOI: $10.2507 / 28$ th.daaam.proceedings. 170

\begin{abstract}
The aim of this contribution is to present some results of the survey in a particular organization that has implemented and certified an integrated management system, and more recently was recertified in accordance with the requirements of new standards ISO 9001: 2015 Quality Management System, ISO 14001: 2015 Environmental Management System and OHSAS 18001 Occupational Health and Safety Assessment Specification. In current approaches to quality and environment management there is accentuated the need of knowledge of an organization and of its management. A novelty in the standards is the so called area of the context and the knowledge of an organization, a part of that is also the change of the organization to the knowledge one in order it to be competitive and unique. Based on these results, we have proposed some measures that would help to the effective fulfilment of the requirements and accession to the knowledge management that could lead to way to be competitive.
\end{abstract}

Keywords: knowledge; management; competitiveness; quality; system; environment

\section{Introduction}

Currently, we are exposed to large turbulence of changes, the stimulus of that are often unexpected changes, in particular, from the external environment. If the organizations want to win the competition and at the same time to handle the pressures, they must focus in particular on human potential that is leading to the so-called learning organization and this is only a step towards the knowledge management.

Today, there is a growing recognition in the business community about the importance of managing knowledge as a critical source for competitive advantage. Researchers in the field of sustainable competitive advantage have discovered that knowledge, that includes what the organization knows, how it uses what it knows, and how fast it can know something new is the only thing that offers an organization a competitive edge. Knowledge is the thermonuclear competitive weapon of our time; knowledge and its management are more valuable and more powerful than natural resources, big factories, or fat bankrolls [5]. 
For the restriction of negative influences on sustainable development assurance, some relevant measures are adopted, that have as a task to inform, mobilize, and regulate an activity to limit or eliminate its influences [7]. A positive approach of business and industry to sustainable development can be increased by economic tools [10]. It requires the environmental oriented monitoring in the manufacturing company and the optimization of management [14]. Information is a specific type of asset that represents value for the company (base for decision making processes) and has to be treated carefully [2]. The concept of knowledge management takes into account all of the above-mentioned areas [6].

The concept of the learning organization is connected with the name of Peter Senge. According to him, the learning organization is the place: "where the people still improve their ability to achieve the desired results, where a flexible and systemic thinking is supported, where people learn and work together" [11].

Learning organization is the one that creates for its people all the conditions, so they can learn anywhere and constantly [1]. However, it is not about an organization that has drawn up a plan of education, and in which all employees are involved in management training. It is the organization's ability to cope with rapid changes, its readiness to respond flexibly and successfully to survive in changing conditions [9].

\section{Knowledge of an organization in the context of the standard ISO 9001: 2015 requirements}

Our present era is characterized by the so-called information revolution, that motivated the governments to recognize its importance and its implications on the development of social, economic, cultural and political [12]. The organization, that is characterized by how readily it is adapting to the market, by transferring the responsibility of deciding on their staff and by readiness to change, can be described as a learning organisation that results in the knowledge management. An organization that learns with the correction of its behaviour and decisions, and in doing so it is based on the information obtained from both the internal and external environment. Internal environment can be, for example, the innovation of new products, the results of the analysis of corporate climate, suggestions or criticism on briefings, financial reports. Important are also some information from the external environment - customer complaints, opening of new markets, new technologies existence, competition proceedings, changes in the customer's interests [8]. The learning organization requires systemically managing knowledge that are specific to the organization. The big positive is the fact that these approaches are already enshrined in the new requirements of the standard ISO 9001: 2015.

\subsection{Approach of managers in a learning organization}

The philosophy of a learning organization requires major changes in the thinking of executives - of managers, at which the role of a manager is changing to the one of a leader. If the manager decides on everything, he does not have to deal with more time-demanding informing the people, with collecting of their views and ideas. This has the advantage for subordinates that, in turn, it is not required of them to be critical or creative thinking; they have just to carry out regulations. With that there is closely related an art to communicate. The keystone of success in good communication is the clarity and intelligibility, for to get things done in a real time [3]. We were based on these ideas when we were performing an analysis of the level of perception of the employees in these areas.

Organizations are increasingly realizing that the learning and development activities must be based on the strategy of the organization. This means that the management is increasingly going to have to put more emphasis on the organizational needs and to allow people to develop so as to promote the implementation of the principles of a learning organization, and not to aim on short-term training activities. Such a learning requires continued and meaningful interaction between people and such a working environment that supports and stimulates learning, and hence the growth of the organization and the individuals in it. It is, however, necessary to make changes, especially in organizations where there is prevalent a tradition of rules, in which the structure, systems and procedures were introduced to maintain stability by preserving the status quo, at any cost.

\subsection{Standard requirements for knowledge management of organisation}

The current approach to the quality management system can be described as an approach to the pursuit of the success and competitiveness of organizations. The chapter 7.1.6 The knowledge of the organization in ISO 9001: 2015 standard is devoted to this area. This is a new requirement of the standard from that it is clear that knowledge of the organization are an important source. According to the ISO 9001:2015: "Organizations shall determine the knowledge that is necessary for the functioning of its processes and for achievement conformity of products and services. In addressing some changing needs and trends, the organizations must consider their current knowledge and determine how to acquire all the necessary knowledge and required updates or how to ensure an access to them. Knowledge of organization can be based on internal resources (intellectual property, knowledge gained through experience, lessons learned from the mistakes and successful projects, collecting and sharing of non-documented knowledge and experience, etc.). It also can be based on external sources, such as participation in conferences, collaboration with academic communities, and the acquisition of knowledge from customers or from other interested parties." 
Management of the organization includes, in particular, the setting of the entire management system - setting values and rules of the organization, setting up an organizational structure, resource management, processes and performance settings. In the interest of the organization is to determine all the necessary management skills of the organization, for knowledge of its employees to be continuously developing and ensured and to be available to all who need them. [15]

\section{Implementation of the requirements of knowledge management and learning organization on the example of a particular production organization}

In the framework of the research projects we carried out, inter alia, a survey of the level of the requirements fulfilment of the knowledge management in a particular production organization. There was determined the level from the perspective of the individual options of personal growth, some opportunities to develop the skills of staff as well as the possibility of using diverse modes of learning.

\subsection{Methodology of the survey}

Analysis (survey) of selected areas, that touches on elements of a learning organization making for knowledge management, was made in the form of a questionnaire in a manufacturing organization with a staff of 320, that means a large organization is concerned. The organization has implemented the system of quality management (STN EN ISO 9001: 2016) [13], of environment (ISO 14001:2015) and of security (OHSAS 18001) management. The survey was attended by 270 employees, i.e. by $75,7 \%$ and was carried out following the recertification to new standards in the field of quality and environment management.

\subsection{Results of the survey and a summary of the results}

The results of the survey (Fig. 1. and Fig. 2.) show that the staff perceives the possibility of personal individual growth and the further professional growth as critical or very important, and demonstrate a level satisfactory of the satisfaction. Figures are tied up or very closely related to each other.

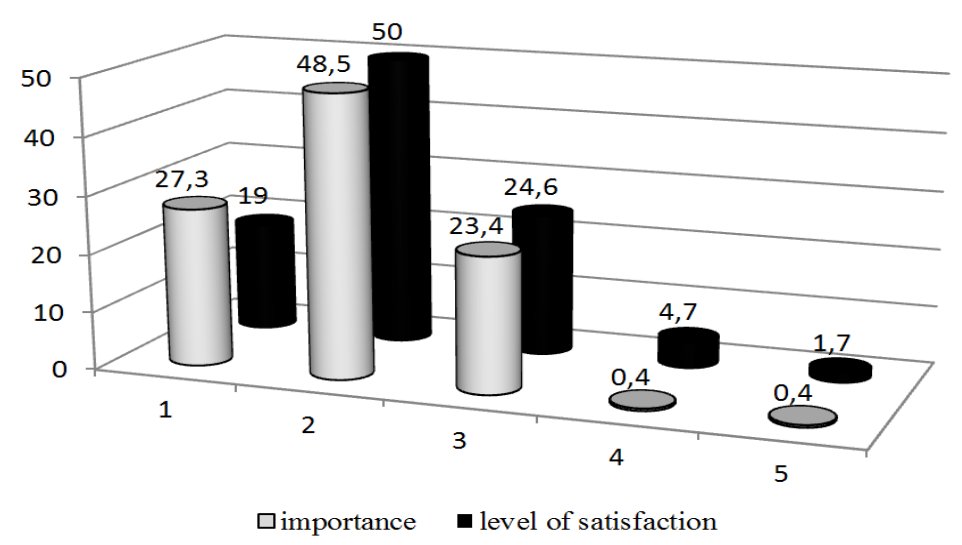

Fig. 1. The ability of an individual's personal growth (date are in \%)

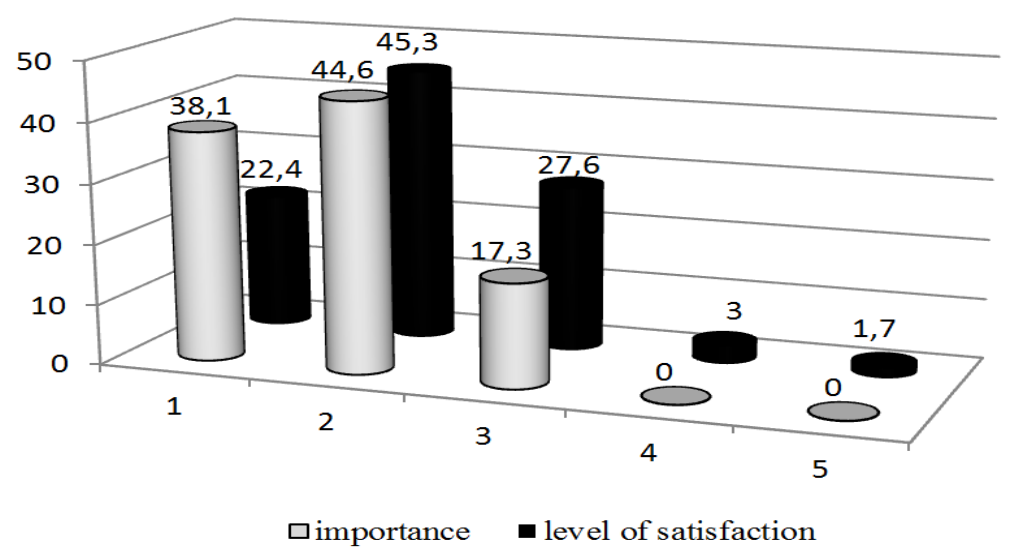

Fig. 2. The ability of professional growth (date are in \%) 
An excellent result - very satisfying - is said by about $20 \%$ of the employees. A third of employees, found the standard condition (they expressed neutrally). From that results that they are not interested in their personal and professional growth. At a more thorough analysis of the individual questionnaires (importance vs. satisfaction rate and education level) there was manifested a kind of a direct link between:

- the importance of personal and professional growth and the level of education,

- the satisfaction with personal development and further education and the level of education.

Direct dependence mostly appeared also between the importance and level of satisfaction (assessment of the importance and degree of satisfaction was almost the same in all cases), however, we believe that employees questioned misunderstood the difference between the importance and satisfaction. For this reason, we focus on the level of satisfaction.

A considerable portion of the interviewed marked a degree of satisfaction - rather satisfied (45-50\%)) and one third of the questioned has declared as neutral (neither satisfied nor unsatisfied). At a more detailed analysis, it was found that the university-educated inquired ones were less satisfied with a personal and further professional development, as confirmed in the responses to the other related issues. The sample given has an interest in constant education and to be competent to carry out their activities and to progress in career growth. The responses at the level of "very happy" have been identified in the sectors that are the support for the production management, that is, in the area of services and administration (mostly covered by education in the field of legislation and laws). Less satisfactory ratings of satisfaction were also identified in the director-general section, where there is included also the top and middle management of organization.

Next survey was focused on the results of the various target groups (depending on the function and level of educational attainment), where they showed direct proportion between greater satisfaction with the diversity of learning and its achievement. Some dependence can also be observed depending on the age of the asked. The survey showed that younger respondents with a university degree expect more possibilities of method or form of learning and they are interested in new lessons also from other areas than professional ones and that could help also to personal development. This is a very good potential of employees to approaching a learning organisation and knowledge management. Similar results we found in the other survey, where most of the organizations ( $72 \%$ ) planned to create the conditions for knowledge management, as a basis for the fulfilment of new approaches to the quality and environment management, leading to an increase in the competitiveness.

Positive outcome of the survey is the fact that the organizations created a good environment for the development of knowledge and experience. There exist some opportunities for further individual education, however, it is not about the systemic approach, but the ad hoc solution. If an organization has an interest in learning organization as a factor of competitiveness, it is necessary to create the systemic approach to the development of knowledge and experience on the basis of certain rules, which the organization determines by itself.

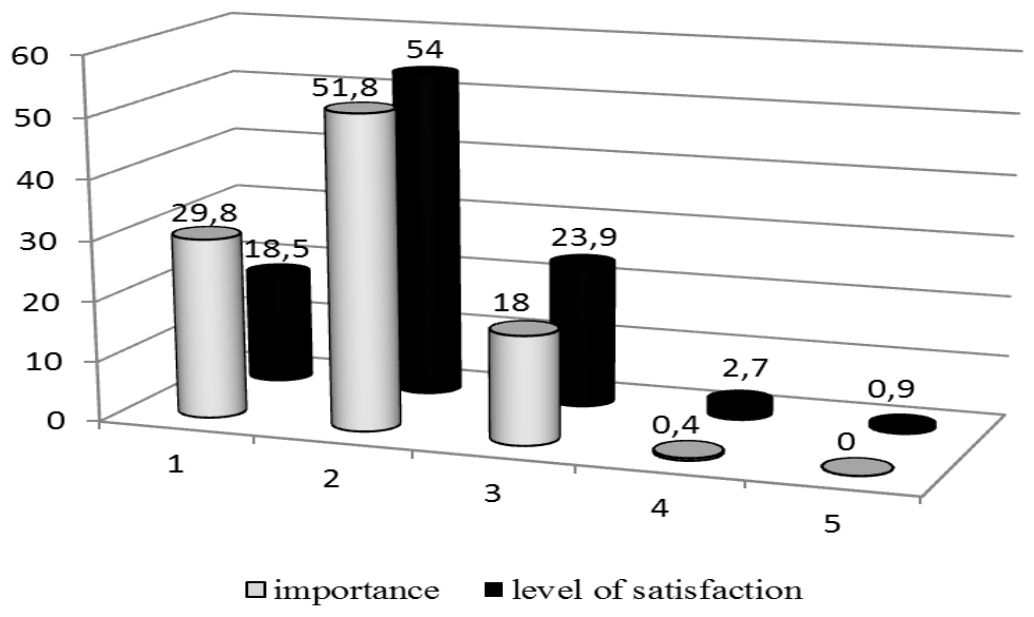

Fig. 3. The use of the knowledge gained by educating

The Figure 3 reflects the attitudes that have been analysed from previous pictures. This figure just confirms the areas and their direct dependence on each area leading to the knowledge management. By comparing the results of individual questions in the survey in a particular organization it has been found and confirmed that the organization that has a culture of a learning organization and has a plan to manage knowledge as a tool for competitiveness, must at first create an environment in organization, that will allow the key employees to meet the expectations in the field of personal development, of continuing professional training, the use of existing knowledge and provide the power to decide at the activities related to the improvement of processes and activities. Key staff should be an example to others, thus ensuring the gradual spread of knowledge to all levels of management and to all employees. 
The key role is primarily of top managers, who have to change their role from managers to the leaders. The basis is, of course, made up of a strategy that is directed toward learning organization as one of the deciding factors of competitiveness.

By comparing the current trends that are processed in specialist publications of significant experts in the field given, as well as the requirements of the new standards on quality and environment management systems, it can be stated, that knowledge management is a way, which is important for improving the competitiveness of the organization.

\section{Opened questions and direction for further research}

The key question is a "will" to create and to record knowledge, because this path is a concept of several timeconsuming steps. The real problems are high and exaggerated expectations of the system itself and also the fact that the concept in this area is still being formed, so it is difficult to define whether the offered system is a knowledge system. Just because someone claims that their information system includes document management features, artificial intelligence and knowledge management does not mean that it is really doing so. [4]

The further way of routing the research in this area should aim to address the following questions:

- Is the management aware of the need for knowledge of the organization as a basis for its growth and competitiveness?

- Are there, in general, identified knowledge in business subjects that is stored in a way so that they are available to all who need them?

- Which requirements and priorities are considered by management when deciding on the knowledge of the organization?

- What is important at the departure of the employees of the company, who are the holders of the key knowledge? What is necessary to ensure for the organization to protect this resource?

We do not consider these questions to be complete and final, but as some starting point of the solution of the issue in theory and practice, as well as a way of adapting to the requirements of the ISO 9001:2015 standard.

\section{Conclusion}

Within the resource-based perspective, information and knowledge have become increasingly recognized as competitive differentiators. In the knowledge-based view, organizational knowledge - such as operational routines, skills or know-how - is acknowledged as the most valuable asset. Currently, an industrial society is transformed into an information society.

The main task of knowledge management is to obtain the "correct" knowledge in the required time for specific employees. For this reason, it is an inevitable requirement of the learning organisations approaching the knowledge management to develop the concept or a system, resp., to ensure a feedback from employees and to listen to their "voice". The organisation must have a corporate culture and create an environment for the possibility of development of knowledge. This fact should be reflected in the values of the organization. If the organization wants to be competitive and manage knowledge sharing for the effective fulfilment of the objectives, it must be reflected in the strategies of the organization, in the form and management methods of its managers (leading to the change of managers to the leaders), in the organization culture, and in the processes in the organization as well. The knowledge management approaching the competitiveness is a matter for the people, of the employees of the particular organization, not the single technology or the use of a quantity of tools and methods that the staff is not able to use and to be uselessly absorbed in the chaos of non-systemic solutions.

Researchers in the field of sustainable competitive advantage have discovered that knowledges of organisation that offers an organization a competitive edge. Knowledge is the competitive force of our time, knowledge and its management are frequently more valuable than natural resources or fat bankrolls.

Knowledge management is based on the fact that the achievement of a sustained competitive advantage depends on firm's capacity to develop and deploy its knowledge-based resources. However, not all resources are equally important for the achievement of this competitive edge. Advance should be based an integrative framework of human capital combining from three different areas of research: knowledge management, intellectual capital, and strategic human resource management. Further research may totally change the focus of knowledge management, but only time will tell about this.

\section{Acknowledgements}

The paper is a part of VEGA 1/0990/15 research project The readiness of industrial enterprises to implement the requirements of ISO 9001: 2015 standards for quality management systems and of ISO 14001: 2014 standards for environmental management systems. in the frame of the project KEGA 048TUKE-4/2015 "Transfer of knowledge from scientific-research activities into multimedia education process" provided by the Ministry of Education, Youth and Sports of the Slovak Republic. 


\section{References}

[1] Author's team. (2002) Knowledge management systems. Theory and practice. Thomson Learning. Barnes S. [Ed.] British Library Cataloguing-in-Publication Data. ISBN 1-86152-616-4.

[2] Cerna, M. (2013) Aspects of Information Management in Context with IS Selection by SME. - In: 24th DAAAM International Symposium on Intelligent Manufacturing and Automation, Katalinic, B. [Ed.] 1877-7058, Published by Elsevier Ltd. Selection and peer-review under responsibility of DAAAM International Vienna doi: 10.1016/j.proeng.2014.03.050

[3] Easterby-Smith, M., Lyle M.A. (2011) Handbook of organizational learning and Knowledge management.. WILEY \&Sons Ltd, Oxford, U.K. ISBN 9780470972809.

[4] Gregor, M., Grznar, P, Pedan, M., Cudrakova, M. (2016) Knowledge in Healthcare. - In: Proceedings of the 26th DAAAM International Symposium, pp.1115-1121, Katalinic, B. [Ed.] Published by DAAAM International, ISBN 978-3-902734-07-5, ISSN 1726-9679, Vienna, Austria. DOI: 10.2507/26th.daaam.proceedings.157

[5] Hurt, U., Tauno O., Kõrbe Kaare K., Koppel O. (2013) New Approach to Knowledge Transfer Environment Development. In: Procedia Engineering, Volume 69/2014, ISSN 1877-7058, Zadar, Croatia, Published by Elsevier, Ltd., p. 273-281.

[6] Mishra,J.K. (2009) Knowledge management: Complexity, Learning and Sustainable. - India. Global India Publications Pvt Ltd. ISBN 978-93-80228-15-0, p. 11.

[7] Moldovan, L. (2015) Sustainability Assessment Framework for VET Organizations. - Sustainability 2015, 7, 71567174. ISSN 2071-105,0 doi:10.3390/su7067156

[8] Petrikova, R. a kol. (2010). Modern knowledge management. - Professional Publishing. Praha. ISBN 978-80-7431011-9. [in Czech]

[9] Rhem,A.J (2017). Knowledge management in Practice. CRC Press. Taylor and Francis Group, New York. ISBN 987-1-4665-6252-3.

[10] Rusko, M., Kralikova, R. (2012) Implementation of environmental management systems in the Slovak enterprises. - In: DAAAM International Scientific Book 2012. Vol. 11, no. 31 (2012), p. 369-378. ISSN 1726-9687.

[11] Senge, P.M. (2014) The Fifth Discipline Field book: Strategies and Tools for Building a Learning organizations. Crown Publishing Group. New York. ISBN 9780804153164.

[12] Shudayfat, E; Moldoveanu, F., Moldoveanu, A. D. B. (2012) A 3D virtual learning environment for teaching chemistry in high school. Annals of DAAAM for 2012 \& Proceedings of the 23rd International DAAAM Symposium, ISSN 1726-9687, ISBN 978-3-901509-86-5, Katalinic, B. [Ed.], Published by DAAAM International, Vienna.

[13] STN EN ISO 9001: 2016: Poziadavky. System manazerstva kvality. [Quality management systems - Requirements] - Bratislava: UNMS SR, 2016 [in Slovak]

[14] Varga, G. \&, Kundrak, J. (2017) Effects of technological parameters on surface characteristics in face milling. In: Solid State Phenomena, 261 SSP, pp. 285-292.

[15] Zgodavova, K., Slimak, I. (2011) Focus on success. - Quality Innovation Prosperity, XV/1 - 2011, pp. 1-4, Accessed July 18th, 2013. [online] Available at: http://www.qip journal.eu/index.php/QIP/article/view/36 